NACIONAL

\title{
El ejercicio del derecho a la vivienda adecuada relacionado con la libertad de asociación: A propósito del caso Figueroa con Comité de Vivienda Los Jardines de Nogales
}

\author{
The exercise of the right to adequate housing linked to the freedom of association: \\ Analysis of Figueroa v. Los Jardines de Nogales' Housing Committee
}

\section{Tatiana Torres (iD)}

Servicio de Vivienda y Urbanización Biobío, Chile

\begin{abstract}
RESUMEN No es desconocido que la perturbación al ejercicio y la directa violación al derecho a la vivienda adecuada es una realidad que se ha manifestado con mayor dureza durante esta pandemia. Tampoco lo es la situación de que los tribunales no otorgan protección jurisdiccional, no ya para exigir su cumplimiento, sino para detener los actos que entorpecen su correcto ejercicio. Este trabajo pretende comentar los aspectos principales de la sentencia de la Corte Suprema del 15 de marzo de 2021, que da luces sobre cómo finalmente un derecho tan íntimamente relacionado con la dignidad humana debe ponerse al centro del razonamiento jurídico en materia judicial.
\end{abstract}

PALABRAS CLAVE Derechos económicos, sociales y culturales, aplicación de tratados internacionales sobre derechos humanos, enfoque de derechos humanos, sentencias judiciales sobre derecho a la vivienda, justiciabilidad.

ABSTRACT It is common knowledge that the infringement of the right to adequate housing is part of our reality and on account of the pandemic, this phenomenon has been severely shown to us. Along with this is the fact that Courts do not provide due legal remedies whether is for ask its fulfillment, or to request the halt of any act that can put at risk its exercise. Regardless of the prior, this work claims to highlight the main aspects of the Supreme Court's ruling of March, 15 of 2021, which sets finally a proper position for the right to adequate housing in the jurisdictional work.

KEYWORDS Economic, social and cultural rights, enforcement of human right's international treaties, human right's approach, courts ruled about the right to adequate housing. 


\section{Introducción}

A propósito de la discusión nacional por el proceso constituyente, presentamos este trabajo sobre el reconocimiento del derecho a la vivienda adecuada, el que, al obtener protección jurisdiccional con las herramientas legales existentes, permite de cierta manera observar avances en materia de protección a los derechos humanos.

Como bien se indicará más adelante, la sentencia que nos convoca fue dictaminada por la Tercera Sala de la Corte Suprema, analizó la vulneración de un derecho consagrado y protegido por la Constitución Política de la República, correspondiente al derecho de asociación, que trae aparejada el entorpecimiento en el ejercicio de otro derecho, que generalmente ha sido considerado no justiciable, cual es el derecho a la vivienda adecuada o digna.

Analizaremos los aspectos más relevantes de la sentencia en comento, para luego introducir conceptos y elementos que configuran el derecho a la vivienda adecuada, como se le conoce en el derecho internacional de los derechos humanos. Lo relevante en este caso es ver ejemplificados ciertos principios de la teoría de los derechos humanos, y cómo de manera paulatina nuestros tribunales se han abierto a aplicar directamente los tratados internacionales sobre derechos humanos ratificados por Chile y que se encuentren vigentes, en virtud de la norma consagrada en el artículo 5, inciso segundo de la Carta Fundamental. ${ }^{1}$

Consideramos que el actuar de la Corte Suprema en este caso sirve de antecedente y viene a constituir un ejemplo de cómo debiese ser el actuar de los órganos del Estado para cautelar la protección por los derechos humanos, y finalmente concretizar la promesa del artículo 1 de nuestra Carta Fundamental.

\section{Hechos que motivan la sentencia}

El recurso de protección que dio origen a la sentencia de que trata este trabajo, causa rol 40.436-2020, fue motivado cuando la recurrente alegó que fue excluida del comité de vivienda Los Jardines de Nogales, del cual formaba parte, a causa de los reclamos que habría presentado por irregularidades al interior del comité.

Por dicha exclusión, la señora Figueroa Pizarro estimó que fue vulnerada la garantía constitucional establecida en el artículo 19, numeral 15 (derecho a asociarse sin permiso previo), entre otras, de la Constitución.

Replicó el comité de vivienda que Figueroa Pizarro realizó requerimientos y re-

1. El artículo 5, inciso segundo de la Constitución Política de la República de Chile dispone que «el ejercicio de la soberanía reconoce como limitación el respeto a los derechos esenciales que emanan de la naturaleza humana. Es deber de los órganos del Estado respetar y promover tales derechos, garantizados por esta Constitución, así como por los tratados internacionales ratificados por Chile y que se encuentren vigentes». 
clamos por cuanto su elección como primera directora de la organización comunitaria no fue tramitada, ya que dicha elección se dio en el contexto de la pandemia por covid-19, aplicándose en cambio la Ley 21.239, que prorrogó los mandatos de las organizaciones, manteniéndose la directiva anterior. De esta manera, a partir de los múltiples conflictos y problemas que generaban las actuaciones de la recurrente, el comité decidió, en asamblea destinada al efecto, expulsarla.

Resulta útil mencionar que los comités de vivienda son organizaciones comunitarias que tienen como objeto propender a que sus miembros puedan acceder a una vivienda digna, teniendo en especial consideración que, para efectos de la postulación al programa habitacional del Fondo Solidario de Elección de Vivienda, establecido en el Decreto Supremo 49 de 2011, del Ministerio de Vivienda y Urbanismo, estas deben tener dentro de sus fines perseguidos la postulación a dicho programa. Por lo tanto, son organismos que fueron gestados con la finalidad de facilitar el ejercicio del derecho a la vivienda adecuada.

Frente a dicho requerimiento, la Segunda Sala de la Corte de Apelaciones de Valparaíso resolvió rechazar el recurso, en atención a que el procedimiento de exclusión había sido ejecutado de conformidad a la normativa que lo regula.

\section{Sentencia en comento}

Como reacción, se elevó una apelación para que la causa fuera conocida por la Corte Suprema, tras lo cual se dictó la sentencia que nos convoca, el 15 de marzo de 2021 por su Tercera Sala, rol 5.168-2021. En la sentencia, la Tercera Sala de la Corte Suprema decidió revocar la sentencia apelada, acogiendo el recurso de protección interpuesto por Claudia Figueroa Pizarro, dejando sin efecto la exclusión dispuesta en su contra por el comité de vivienda Los Jardines de Nogales.

Es en esta sentencia cuando encontramos un razonamiento concordante con las obligaciones internacionales contraídas por Chile, en virtud de los tratados internacionales sobre derechos humanos que han sido ratificados por el país y que se encuentran vigentes. Lo que hace la Corte es razonar en torno a la proporcionalidad de la sanción impuesta a la recurrente y la consecuencia que esta trae aparejada en el ejercicio del derecho a la vivienda adecuada o digna.

Así, en su resuelvo cuarto dispone que, para efectos de una adecuada resolución del asunto, parece indispensable reparar en las consecuencias que la exclusión conlleva para un miembro de un comité de vivienda. Infiere el tribunal que la finalidad implícita de dichas organizaciones es la obtención de una vivienda digna.

Además, señala en su considerando quinto que la pertenencia a este tipo de órganos tiene directa incidencia en el derecho de todo asociado a contar con una vivienda digna, garantía que se encuentra prevista en el artículo 25, ordinal primero de la Declaración Universal de Derechos Humanos. Para reforzar la existencia del de- 
recho a la vivienda adecuada, el tribunal hace referencia también a lo establecido en el artículo 11 del Pacto Internacional de Derechos Económicos, Sociales y Culturales, ratificado por Chile y que se encuentra vigente.

De esta manera razona que la expulsión, en las propias palabras del considerando sexto, es la máxima sanción estatutaria posible de aplicar, y que por tanto exige la concurrencia de razones de una intensidad tal que permitan derrotar la legítima expectativa del individuo sancionado a satisfacer su derecho a contar con una vivienda digna. Intensidad que no se vislumbra en los hechos, pues en la conducta que se le atribuye a la actora, como bien menciona en su considerando séptimo, no se aprecian consecuencias concretas que impliquen un perjuicio para el comité o para el resto de sus integrantes, sino, al contrario, los hechos que fueron utilizados como justificación para la expulsión no importan una merma evidente para el fin que ha de alcanzar la organización.

Finalmente, en su considerando octavo, el máximo tribunal califica la medida expulsiva aplicada a la recurrente como manifiestamente desproporcionada, en especial si se considera la alta importancia de pertenecer a la organización comunitaria de que se trata, necesaria para el acceso de sus integrantes a una vivienda digna.

\section{Derecho a la vivienda adecuada o digna, a propósito de la sentencia}

Que la Corte Suprema reflexione en torno al ejercicio del derecho a la vivienda adecuada o digna es un reconocimiento al hecho de que los tratados internacionales sobre derechos humanos ratificados por Chile y que se encuentren vigentes son efectivamente aplicables por la vía del artículo 5 , inciso segundo de la Constitución.

El derecho a la vivienda adecuada es posible encuadrarlo dentro de los conocidos como derechos sociales, y está establecido en diversos tratados internacionales, entre ellos, el Pacto Internacional sobre Derechos Económicos, Sociales y Culturales (PIDESC), que establece en su artículo 11, párrafo primero, que «los Estados parte en el presente Pacto reconocen el derecho de toda persona a un nivel de vida adecuado para sí y su familia, incluso alimentación, vestido y vivienda adecuados, y a una mejora continua de las condiciones de existencia».

Dicho derecho, según el Comité de Derechos Económicos, Sociales y Culturales de Naciones Unidas en su Observación General núm. 4, «no se debe interpretar en un sentido estricto o restrictivo que lo equipare, por ejemplo, con el cobijo que resulta del mero hecho de tener un tejado por encima de la cabeza o lo considere exclusivamente como una comodidad. Debe considerarse más bien como el derecho a vivir en seguridad, paz y dignidad en alguna parte».

En la misma observación general, el Comité identificó algunos aspectos que conlleva el derecho a la vivienda adecuada, los que son: seguridad jurídica de la tenencia; 
disponibilidad de servicios, materiales, facilidades e infraestructuras; gastos soportables, habitabilidad; asequibilidad; lugar y adecuación cultural.

De acuerdo con Gil (2020: 866), «la lista de los distintos aspectos que involucra el derecho a una vivienda adecuada revela que las obligaciones contenidas en este derecho no se agotan con la entrega de un espacio habitable», lo que refiere a que el Estado tiene la obligación de dar protección legal frente a casos de desalojo, como incluir la pretensión de que las personas estén localizadas en lugares que estén adecuadamente conectados con servicios públicos y privados.

Por su parte, la legislación nacional, en especial la Ley General de Urbanismo y Construcciones, ha mirado la vivienda enfocándose en su estructura más que en su funcionalidad, lo que se condice con el enfoque que se la ha dado a la vivienda en la política habitacional chilena. Dándole importancia a la superficie efectivamente construida, esta ley, unida a la ordenanza, constituyen la base desde donde se planifican los programas que articulan el acceso a la vivienda en Chile.

Sin perjuicio de la conceptualización que en la legislación y doctrina chilena se ha hecho del derecho a la vivienda adecuada, es del caso relevar la importancia de esta sentencia en cuanto a que la existencia y formas de asociación relacionadas con los comités de vivienda constituye la forma mediante la cual hoy se logra tener acceso a una vivienda por parte de la población en urgente necesidad habitacional, como la caracterizan los programas habitacionales del Ministerio de Vivienda y Urbanismo (Minvu).

Los programas habitacionales actuales del Minvu exigen que para efectos de las postulaciones colectivas a los subsidios para obtener una vivienda que otorga el Estado, las personas deban estar agrupadas en organizaciones que gocen de personalidad jurídica propia y que hayan sido formadas con tal objeto. Los comités de vivienda pasan a ser entonces el vehículo exclusivo para el ejercicio del derecho a la vivienda adecuada, mediante el cual las familias puedan acceder a mejorar sus condiciones habitacionales, permitiendo la posibilidad de participar en el diseño y proceso constructivo de sus viviendas.

Es del caso tener en consideración que el ejercicio del derecho a la vivienda adecuada o digna compromete y afecta el ejercicio de otros derechos, por lo que es posible relacionarlos. En este sentido, se ha dicho que «es importante destacar, además, que el derecho a la vivienda no se entiende en solitario, sino que está intrínsecamente ligado a otros derechos humanos» (Silva y otros, 2020: 20). Así también lo ha señalado Espejo (2010: 53) al mencionar que, «a su vez, en virtud de los principios de universalidad e indivisibilidad de todos los derechos humanos, el derecho a la vivienda adecuada no debe ser considerado aisladamente, sino que su interpretación y aplicación debe resultar congruente con el respeto, garantía y satisfacción de otros derechos humanos». De esta forma, la relación que hace el fallo de la Corte Suprema nos parece del todo acertado, pues el derecho a asociación, que permite a las familias 
formar parte de un comité de vivienda, al ser obstaculizado, impide el ejercicio del derecho a la vivienda, como se indicó en párrafos anteriores.

Con base en el principio de la interdependencia, ${ }^{2}$ podemos observar la manifiesta relación entre los derechos civiles y políticos, y los derechos económicos, sociales y culturales (DESC), lo que ha sido siempre parte de la doctrina de la ONU. Esto se puede constatar con la dictación de la Declaración Universal de Derechos de 1948, la que incluyó ambas categorías sin manifestación alguna de signos de separación o prioridad entre ellos (Alston y Goodman, 2013: 285).

En nuestro texto constitucional no se encuentra expresamente consagrado el derecho a la vivienda adecuada, lo que nos plantea la problemática respecto de su justiciabilidad. Para algunos, no solo no es posible ir directamente ante un tribunal para exigir el cumplimiento del derecho referido, sino que tampoco es posible obtener una protección frente a intervenciones o perturbaciones en su ejercicio; en tal sentido, es necesario recorrer un "camino más largo», relacionando la vivienda con otro derecho que sí se encuentre consagrado y protegido.

Esto último no deja de llamarnos la atención, en especial teniendo en consideración lo referido por Alston respecto a la Declaración Universal de Derechos de 1948. ¿Realmente es necesario vincular un derecho con otro para obtener su protección? ¿Existe entonces una especie de jerarquización de los derechos humanos, en que algunos son más importantes que otros $y$, por tanto, solo algunos son dignos de protección? Con estas preguntas no estamos descubriendo la rueda, pues el caso ya ha sido cuestionado por la anterior relatora especial para la vivienda adecuada en su visita a Chile y que consta en su informe del 17 de enero de 2018, al hacer patente que «en Chile, los derechos económicos, sociales y culturales siguen estando subordinados a los derechos civiles y políticos». ${ }^{3}$ Mismo razonamiento se ha descrito por la anterior en el informe "Acceso a la justicia para la defensa del derecho a la vivienda», al indicar que «en la medida en que deniegan el acceso a la justicia para la defensa del derecho a la vivienda, los Estados perpetúan una jerarquía de derechos humanos, lo que pone de manifiesto una situación de discriminación, en el sentido de que algunos derechos son más importantes que otros». ${ }^{4}$

Para Alston, los DESC han asumido una mayor relevancia constitucional en variados países a partir de un reconocimiento constitucional explícito o una interpre-

2. Para aquellos que quieran ahondar en la relación entre los derechos y de estos con el concepto de ciudadanía, recomiendo el artículo de Marshall (2017).

3. "Informe de la relatoría especial sobre una vivienda adecuada como elemento integrante del derecho a un nivel de vida adecuado y sobre el derecho de no discriminación a este respecto relativo a su misión en Chile», Consejo de Derechos Humanos, A/HRC/37/53/Add.1, 17 de enero de 2018, p. 18, disponible en https://undocs.org/es/A/HRC/37/53/Add.1.

4. «Acceso a la justicia para la defensa del derecho a la vivienda», Consejo de Derechos Humanos, A/ HRC/40/61, 15 de enero de 2019. p. 21, disponible en https://www.undocs.org/es/A/HRC/40/61. 
tación judicial de los derechos civiles y políticos que comprenda al menos algunos DESC; y una voluntad por parte de los tribunales para tratar como justiciables a los derechos sociales, antes considerados no justiciables (Alston y Goodman, 2013: 330). El Comité de los DESC, en su Observación General núm. 9, ha manifestado que respecto a estos derechos se parte del supuesto de que no es fundamental la existencia de recursos judiciales frente a las violaciones de estos derechos, situación que sí ocurre con los derechos civiles y políticos. Agregan que, sin embargo, dicha distinción no tiene justificación, pues incluso hay disposiciones del Pacto que pueden aplicarse inmediatamente, distinguiendo entre justiciabilidad, «que se refiere a las cuestiones que pueden o deben resolver los tribunales», y las normas de aplicación inmediata, «que permiten su aplicación por los tribunales sin más disquisiciones».

En dichos del Comité de los DESC, «no hay ningún derecho reconocido en el Pacto que no se pueda considerar que posee en la gran mayoría de los sistemas algunas dimensiones significativas, por lo menos, de justiciabilidad». Que como país lleguemos a la conclusión que cualquiera de los DESC, o que el derecho a la vivienda adecuada en específico carece de protección judicial o legal, sería «arbitrari[o] e incompatible con el principio de que los dos grupos de derechos son indivisibles e interdependientes».

La justiciabilidad de los DESC no es un tema pacífico en la doctrina, pero ha sido analizado con seriedad por variados autores, como Abramovich y Courtis (1997), al hacerse cargo de las objeciones respecto a si estos derechos son reclamables ante los tribunales de justicia. Indican que la línea entre los derechos civiles y políticos y los DESC no es tan clara como aparentan, por lo que es posible entender que en ambos casos se cuenta con el derecho al recurso judicial y a no ser discriminado en su ejercicio. Se entiende además que, respecto a los DESC, los Estados tienen la obligación de adoptar medidas inmediatas, de garantizar niveles esenciales de los derechos, y de progresividad y prohibición de regresividad. Frente a lo anterior, de consideración resulta tener a la vista la jurisprudencia de la Corte Interamericana de Derechos Humanos, en los casos Lagos del Campo con Perú, respecto al derecho al trabajo, o Cinco Pensionistas con Perú en cuanto al derecho a la seguridad social, ${ }^{5}$ en que la Corte reconoce la posibilidad de accionar frente al incumplimiento de un Estado de su obligación de respetar un derecho social, en virtud de lo establecido en el artículo 26 de la Convención Americana sobre Derechos Humanos.

Esta idea, entonces, de que existen derechos más importantes que otros, ${ }^{6}$ y que

5. Sentencia del caso Cinco Pensionistas con Perú, Corte Interamericana de Derechos Humanos, fondo, reparaciones y costas, 28 de febrero de 2003.

6. Este no es un tema pacífico en la doctrina, es posible encontrar argumentos a favor o en contra de la justiciabilidad de los derechos sociales. Cobra relevancia para este trabajo, sin perjuicio de que por razones de extensión no es posible analizarlo, lo indicado por Atria (citado por Marshall, 2017: 115), en 
ha sido reforzada en la práctica al carecer de una jurisprudencia directamente relacionada con la vivienda, ${ }^{7}$ nos obliga a meditar respecto a que como país debemos reconocer y consagrar en nuestro texto constitucional este derecho tan íntimamente relacionado con la dignidad del ser humano.

Sin embargo, entendemos también que su falta de reconocimiento no es óbice para que el Estado cumpla con las obligaciones internacionalmente contraídas, puesto que no es posible argüir disposiciones de nuestro derecho interno (o la falta de ellas) para no cumplir con las obligaciones de los tratados, como bien nos manifiesta el artículo 27 de la Convención de Viena. Así entonces, que no reconozcamos como derecho fundamental el derecho a la vivienda adecuada, ni constitucional ni legalmente (Smart y Burgos, 2020: 19), no le quita su carácter de derecho humano, y no es impedimento para que vía artículo 5 , inciso segundo de la Constitución se entienda garantizado y deba ser tomado en consideración, tanto al momento de articular las políticas públicas que facilitan su ejercicio, como para facilitar los remedios judiciales o administrativos que permitan su protección.

Es en este punto en que la sentencia del 15 de marzo de 2021, dictada por la Tercera Sala de la Corte Suprema, brilla con un esplendor especial. No solo relaciona el ejercicio de un derecho consagrado en el artículo 19 de la Constitución con el derecho a la vivienda adecuada o digna, reconociendo el carácter interdependiente de los derechos humanos; sino que también realiza una aplicación basada en el artículo 5, inciso segundo de la Constitución, abriendo el catálogo de derechos a aquellos contenidos en los tratados internacionales ratificados por Chile y que se encuentran vigentes, como lo es el PIDESC.

\section{Conclusión}

Lo que hace la Corte Suprema en este fallo es reconocer la relevancia que en el ejercicio de su rol tienen los derechos humanos, respecto al cambio de prisma de los jueces con el cual se miran los DESC. Así también se ha recomendado en las directrices sobre las políticas de vivienda, contenidas en el informe «Directrices para la aplicación del derecho a una vivienda adecuada», que señala que, «en el ejercicio de sus funciones de examen judicial, los tribunales deberían adoptar interpretaciones de la legislación nacional que fuesen compatibles con el derecho a la vivienda». ${ }^{8}$

Tiene sentido que así lo haya resuelto la Corte Suprema, pues dentro de las garan-

cuanto la exigibilidad de los derechos sociales no depende de la posibilidad de reclamarlos judicialmente, dado que esta es un tipo de práctica que sirve para adjudicar derechos individuales, y no derechos sociales.

7. $\mathrm{CDH}$, «Informe...», 18.

8. «Directrices para la aplicación del derecho a una vivienda adecuada», Consejo de Derechos Humanos, A/HRC/43/43, 26 de diciembre de 2019, p. 5, disponible en https://undocs.org/es/A/HRC/43/43. 
tías vulneradas y reclamadas por la recurrente, se encontraba la libertad de asociación, consagrada como derecho en el artículo 19, numeral 15, como el derecho a asociarse sin permiso previo. Dicho derecho aparece además mencionado en el artículo 20 de la Declaración Universal de los Derechos y en el artículo 22, párrafo primero del Pacto Internacional sobre Derechos Civiles y Políticos, vigente en Chile en virtud del Decreto Supremo 778 de 1989.

$\mathrm{Al}$ asociarse a una organización comunitaria como un comité, cuyo fin último es servir de vehículo para que sus miembros puedan acceder a una vivienda digna, la recurrente pudo plantear el vínculo existente entre que se le haya privado de su derecho a la libre asociación, al ser expulsada del comité de vivienda sin fundamento serio y suficiente, y lo que esta privación significa para el ejercicio a una vivienda adecuada.

La Corte hace un ejercicio de ponderación acerca de la gravedad de la sanción impuesta por la directiva y asamblea del comité de vivienda, en relación con los hechos que se le imputaban a la recurrente, y cómo todo esto vulneró el ejercicio su derecho a la vivienda digna. Efectivamente se vulneraron ambos derechos, puesto que la sanción impuesta fue desproporcionada en atención a la conducta desplegada, y dicha expulsión conllevó la perturbación respecto al derecho a la vivienda, al no poder ejercerlo porque ya no conformaba parte del grupo organizado exigido por la política habitacional correspondiente.

Como es posible observar, estamos frente a una expresa manifestación del principio de interdependencia de los derechos humanos, y de un claro reconocimiento por parte del máximo tribunal del país de que es posible proteger un derecho no contemplado expresamente en el catálogo de los derechos protegidos por el recurso de protección, y que la aplicación de los tratados internacionales sobre derechos humanos ratificados por Chile y que se encuentren vigentes, en virtud de lo dispuesto en el artículo 5, inciso segundo de nuestra Carta Fundamental, es una herramienta plenamente útil para el objeto de cautelar la igual protección de la ley en el ejercicio de los derechos.

Dicha labor de respeto por los derechos humanos no tan solo es exigible a los funcionarios judiciales, sino también a todo aquel órgano que forme parte de la Administración del Estado. En este sentido, conviene tener a la vista lo dispuesto por el artículo 1 de la Constitución, en cuanto «el Estado reconoce y ampara a los grupos intermedios $[\ldots]$ y les garantiza la adecuada autonomía para cumplir sus propios fines específicos».

La Corte Suprema reconoce en su fallo la importancia del grupo intermedio que corresponde al comité de vivienda, y sin perjuicio de que estos gozan de protección constitucional en cuanto a su autonomía para cumplir con sus fines, esto no los habilita para perturbar o entorpecer, sin fundamento suficiente, el ejercicio de los derechos de sus miembros.

Dicho lo anterior, nos sorprende lo resuelto por la Contraloría General de la Re- 
pública, en tanto dictamina, a propósito de un procedimiento de exclusión de miembros de un comité de vivienda que fue recogido por el Servicio de Vivienda y Urbanización (Serviu) correspondiente mediante la eliminación de dichos miembros de la nómina de beneficiarios, que ejercer dicha facultad de expulsión corresponde de manera privativa al comité que integraba el reclamante. ${ }^{9}$ Por lo anterior, no corresponde ni al Serviu ni a Contraloría referirse a la legalidad de dicha exclusión.

No podemos estar en mayor desacuerdo con esta decisión, pues, como se ha venido indicando en el análisis de esta sentencia, corresponde a los órganos del Estado dar cumplimiento a las obligaciones contraídas por ellos en los tratados internacionales sobre derechos humanos. No es posible excluir a órgano alguno de dicha obligación, sino, por el contrario, debiese ser cada institución del Estado la que ejerza un control de convencionalidad ${ }^{10}$ al momento de tomar decisiones que puedan afectar en el ejercicio de los derechos de las personas.

En el caso en concreto, la situación podría haberse evitado si el Serviu, antes de eliminar de las nóminas de beneficiarios a los expulsados, verificara que las medidas de expulsión son proporcionadas y considerara si dicho acto vulnera el ejercicio del derecho a la vivienda adecuada, cuando carece de justificación suficiente. Difícilmente el Serviu o cualquier otro órgano de la Administración del Estado realizará dicha labor si existen dictámenes como el 23.470 de 2016 de Contraloría General de la República, que resultan obligatorios para la Administración Pública.

Por último, agregar que no obstante la compleja situación respecto al ejercicio del derecho a la vivienda adecuada en este último tiempo, en especial agravada por la pandemia, creemos que la existencia real de este derecho se hace más patente que nunca, sirviendo sentencias como esta para detener las excusas y cuestionamientos acerca de su aplicabilidad, y abriendo el camino para que los derechos humanos sean efectivamente el centro de las políticas públicas de nuestro país.

\section{Referencias}

Abramovich, Victor y Christian Courtis (1997). «Hacia la exigibilidad de los derechos económicos, sociales y culturales: Estándares internacionales y criterios de aplicación ante los tribunales locales». En La aplicación de los tratados sobre derechos humanos por los tribunales locales (pp. 283-350). Buenos Aires: Editores del Puerto.

Alston, Philip y Ryan Goodsman (2013). International human rights: The successor to international human rights in context. Oxford: Oxford University Press.

Espejo, Nicolas (2010). «El derecho a una vivienda adecuada». Revista CIS, 8 (13): 48-62. Disponible en https://bit.ly/36OU4Tn.

9. Contraloría General de la República, Dictamen 23.470 de 2016.

10. Sobre el tema, recomendamos Contreras y García (2020). 
GiL, Diego (2020). «Derecho a la vivienda» En Pablo Contreras y Constanza Salgado (editores), Curso de derechos fundamentales (pp. 857-887). Valencia: Tirant Lo Blanch.

Marshall, Pablo (2017). «Clasificación de los derechos fundamentales». En Pablo Contreras y Constanza Salgado (editores), Manual sobre derechos fundamentales: Teoría General (pp. 93-118). Santiago: Lom.

Silva, Ignacio, Paz Zúñiga, Florencia Vergara, Yessenia Millones, Matthias Casasco, María Herrera, Vicente Silva y Valentina Contreras (2020). Habitar en dignidad, hacia el derecho a la vivienda en la nueva Constitución. Santiago: Techo Chile, Fundación Vivienda y GI-ESCR.

SMART, Sebastián y Vicente Burgos (2020). «Política de vivienda chilena: Una perspectiva de derechos humanos pendiente». Revista CIS, 28: 13-29. Disponible en https://bit.ly/2UXMpzp.

\section{Sobre la autora}

Tatiana Torres es abogada de la Universidad de Concepción, Chile. Diplomada en Gestión de Políticas Sociales por la Universidad de Concepción. Diplomada en Derechos Humanos y Función Pública, Universidad del Biobío, Chile. Analista jurídica del Servicio de Vivienda y Urbanización (Serviu), región del Biobío. Su correo electrónico es tatitorresmontenegro@gmail.com. (D) https://orcid.org/oooo-0002-8153-4906. 
El Anuario de Derechos Humanos es una publicación semestral de referencia y consulta en materia de derechos humanos y campos afines. Busca ser un espacio de discusión de los temas centrales en el ámbito nacional e internacional sobre derechos humanos. Es publicado desde 2005 por el Centro de Derechos Humanos de la Facultad de Derecho de la Universidad de Chile.

\author{
EDITORA \\ Claudia Iriarte Rivas \\ ciriarter@derecho.uchile.cl \\ SITIO WEB \\ anuariocdh.uchile.cl \\ CORREO ELECTRÓNICO \\ anuario-cdh@derecho.uchile.cl \\ LICENCIA DE ESTE ARTÍCULO \\ Creative Commons Atribución Compartir Igual 4.o Internacional
}

\author{
\% \\ La edición de textos, el diseño editorial \\ y la conversión a formatos electrónicos de este artículo \\ estuvieron a cargo de Tipográfica \\ (www.tipografica.io)
}

